\title{
A bad trade: Mitral regurgitation for mitral stenosis and atrial fibrillation
}

\author{
Marc Gillinov, MD, Per Wierup, MD, PhD, and Stephanie Mick, MD
}

\footnotetext{
From the Department of Thoracic and Cardiovascular Surgery, Cleveland Clinic, Cleveland, Ohio. Disclosures: Authors have nothing to disclose with regard to commercial support.

Received for publication Aug 20, 2018; accepted for publication Aug 21, 2018available ahead of print Sept 26, 2018.

Address for reprints: Marc Gillinov, MD, Department of Thoracic and Cardiovascular Surgery, Cleveland Clinic/ Desk J4-1, 9500 Euclid Ave, Cleveland, OH 44195 (E-mail: gillinom@ccf.org).

J Thorac Cardiovasc Surg 2019;157:928-9

$0022-5223 / \$ 36.00$

Copyright (c) 2018 by The American Association for Thoracic Surgery

https://doi.org/10.1016/j.jtcvs.2018.08.036$$
\text { (ps//doi.org/10.1016/j.jtcus.2018.08.036 }
$$

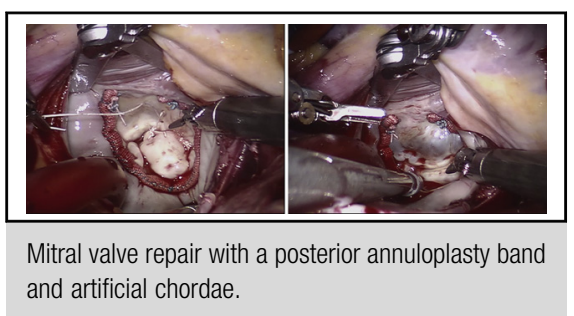

Central Message

Mitral valve repair techniques should be chosen to eliminate MR and prevent MS, because elevated postrepair gradients predispose to $\mathrm{AF}$.

See Article page 921.
Atrial fibrillation (AF) and mitral valve disease travel together. In the presence of mitral regurgitation (MR), the development of $\mathrm{AF}$ is an indication for operation. Conversely, mitral valve surgery in those with no history of AF often engenders the development of perioperative AF. In this issue of the Journal, Ma and associates ${ }^{1}$ add another chapter to this story; they demonstrate an association-presumably causal-between increased postrepair mitral gradients and the development of late AF. Surgeons have long recognized that cardiac surgery can cause transient postoperative AF, but now we must accept that our operations (and specific operative techniques) also can cause late persistent $\mathrm{AF}$.

When operating for degenerative mitral valve disease, the surgeon focuses on MR rather than on mitral stenosis (MS); after all, severe MR is the surgical indication in these patients (Figure 1). The prerepair echocardiogram, choice of repair techniques, and postrepair echocardiogram all center on the assessment and treatment of MR. In particular, the postrepair echocardiogram seeks to identify any residual MR and often includes only a brief assessment of the transmitral gradient. Ma and associates ${ }^{1}$ suggest that surgeons should pay more attention to the transmitral gradient, because it turns out that this value affects patient outcomes.

A normal mitral valve has a transmitral gradient of 0.8 to $2.7 \mathrm{~mm} \mathrm{Hg}{ }^{2}$ Previous work suggests that a gradient exceeding $3 \mathrm{~mm} \mathrm{Hg}$ can result in impaired exercise tolerance. ${ }^{2}$ Adding to this observation, $\mathrm{Ma}$ and colleagues ${ }^{1}$ found that a gradient exceeding $4.5 \mathrm{~mm} \mathrm{Hg}$ substantially increases the risk of late AF. Taken together, these findings suggest that the surgeon should repair the valve using techniques that correct MR and prevent MS. Ma and colleagues help with this task by identifying repair techniques associated with higher gradients.

In patients with degenerative disease, the use of a small, complete annuloplasty ring, incorporation of an edge-toedge repair, and closure of clefts/indentations were associated with elevated transmitral gradients. In contrast, use of
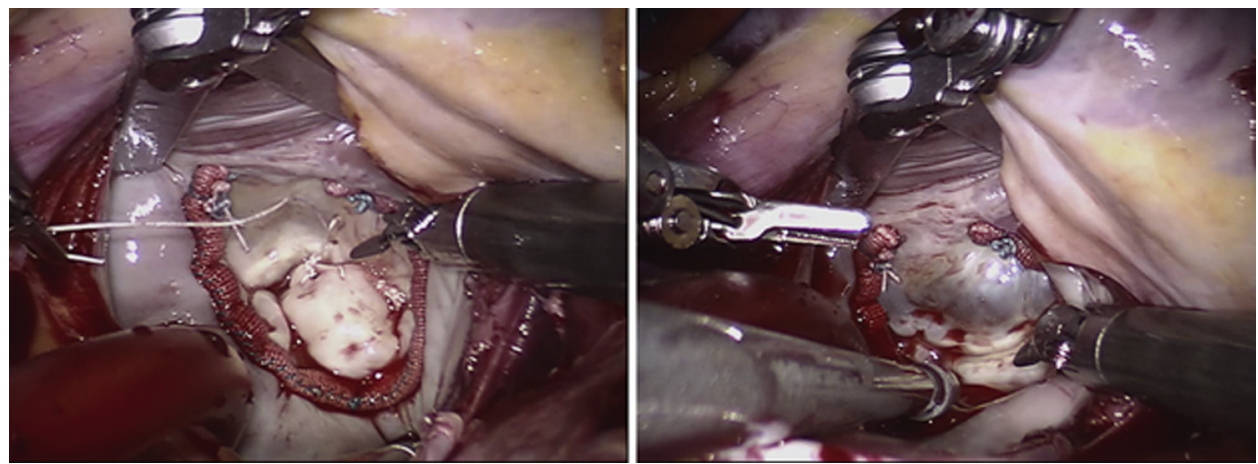

FIGURE 1. Mitral valve repair with flexible band and artificial chordae by robotic approach. Left: Annuloplasty band in place, artificial chordae to posterior leaflet being tied. Right: Appearance at valve testing with saline insufflation. 
an appropriately sized annuloplasty band did not cause high gradients. These findings provide guidance for the mitral repair surgeon. Given the paucity of evidence supporting the superiority of any particular annuloplasty device in patients with degenerative disease, surgeons should use a flexible annuloplasty band in most of these patients. Closing clefts/indentations can turn the posterior mitral leaflet into a tightly drawn, stiff structure; in our experience, use of artificial chordae to correct posterior prolapse generally obviates the need to close clefts and thereby avoids this outcome. Finally, the edge-to-edge repair may not be an ideal choice as a primary repair technique in patients with a relatively small valve orifice.

The implications of Ma and colleagues' work ${ }^{1}$ extend beyond surgical repair of degenerative disease. As with aortic valve replacement, when performing mitral replacement, it may be prudent to choose the largest and most hemodynamically efficient prosthesis to avoid elevated gradients. Likewise, percutaneous repairs that substantially reduce the mitral orifice area (eg, application of 2 or more MitraClips [Abbott, Abbott Park, Ill]) may increase the likelihood of late AF.

With this important article, Ma and colleagues ${ }^{1}$ remind us that our goal is to repair the mitral valve rather than to trade MR for an elevated gradient (MS) that can leave our patients with reduced exercise tolerance and an increased future risk of AF.

\section{References}

1. Ma W, Shi W, Wu W, Ye W, Kong Y, Zhu D, Zhang W. Elevated gradient after mitral valve repair: the effect of surgical technique and relevance of postoperative atrial fibrillation. J Thorac Cardiovasc Surg. 2019;157:921-7.

2. Chan KL, Chen SY, Chan V, Hay K, Mesana T, Lam BK. Functional significance of elevated mitral gradients after repair for degenerative mitral regurgitation. Circ Cardiovasc Imaging. 2013;6:1041-7. 